\title{
Mental Outcome and Behavior in Primary School Education
}

\author{
Abbas Alaji* \\ Consultant Neurosurgeon Al sadir medical city, Iraq \\ *Corresponding author: Abbas Alaji, Consultant Neurosurgeon Al sadir medical city, Iraq
}

\begin{abstract}
Pre- ( kindergarten) and Primary school learning and education facing many obstacles in all communities with different grades and modalities, these range from inattention ( loss of concentration) to the given learning material or programs to the aggressive attitude towards any target, here I want to shed some light on what could be the cause behind such child unfavorable mental cognitive and psychology which could be all due to some low grade cerebral affection, this in my studies are due to intracellular ( neuronal, glial or other somatic cells) bacterial chronic affection.
\end{abstract}

Keywords: Child Education; Child Learning; Child Mental Health; Bringing Up; Aggression; Hostility; Anxiety

\section{Introduction}

Many families and educational institutes suffer from the child mental outcome which ranges from the lack of concentration on the given programs whatever they are or the difficulty in memorization of what had been taught or is studied, to the hostile aggressive behavior directed to any target. Of course it is multi-factorial or multi-disciplinary. Here I want to stress on the organic factors of the general health aspect. In case we have the status of being affected by an early or child bearing infections of low grade type that bring to a sub-clinical impaired general or mental health. This condition is of high prevalence in my work on the biological bases of neurosurgical pathologies represented by a chronic brucellosis at the beginning by clinical examination and trial treatment then by open tissue biopsy for PCR study.

\section{Material and Method}

For the last twenty years of my studies on the real causation of the medical and surgical conditions made me concentrate on many conditions other than neurosurgical entities just like by opening one door it opens doors as a result to reveal the nature or see what was known to be un-known!! So according to this I realized that the poor outcome of children is due to this chronic or dormant infections that was obtained by applying the vision of sub-clinical intracellular infections in all patients of such field clinically for all (the number is several tens of both gender of pre- and primary school age). Five males underwent PCR tissue biopsy very recently.

\section{Results}

Those whom based on clinical examination with apparent findings goes with the above hypothesis had a clear change in their condition with which we started in a positive encouraging degree. Those who do not show symptoms or signs suggesting what I am saying as being a victims to a chronic sub-clinical intracellular general infection, when subjected to the same trial treatment for Brucella due to the encouraging positive results of the a fore mentioned group ( a part from the percentages due to the lack of detailed data base of this study simply because it is not my strict field of work, the patients sample is a random one consisted from families of my relatives, friends or that whom hear about the successes and come to my private clinic. By this I want just to share with the interested workers these words), the results in those sufferers of mental and behavioral difficulties is very remarkably noticeable to show that this factor of being sub-clinically affected is not far from the truth if not it is the full and only truth, but it is under estimated. PCR of an open trapezius muscle biopsy done 
for five patients only due to high cost, all are males 4-8 years of age two of five showed Brucella positive, negative PCR results dose not exclude positively ( false negative) or could be due to other pathogens our real time PCR kit is for Brucella only, I do my best to encourage the lab to develop to screen for more than Brucella ( fifteen intra-cellular bacteria).

\section{Discussion}

Mental deviation in general should have a cause. Logically there should be a main or principal cause and an aggravating or precipitating factors. So, all other social and environmental factors other than the sub-clinical infection is the precipitating factors and the principal one is the chronic sub-clinical bacterial infection whether in brain parenchyma ( neurons and glial cells) or in the somatic cells and exhibit their effect by some mode on the central nervous system cognitive and psychological function. Anxiety is being one of these un-wanted events, it has a dual effect as being one manifestation to the sub-clinical infection and in same time act as a profound stress on the nervous and immune systems to deepen the bad effect of the systemic infection and hence on the general health. It had been said the SOUND MIND IN THE SOUND BODY. The results of my clinical trials and the few cases with positive PCR for Brucella give a deep meaning to the underlying cause behind the problems the communities are subjected to however differently, but the soul is one. Low grade cerebritis focal or global caused by Brucella (and the other intracellular bacteria) is the real biological platform for the mental impairments, the mechanisms involved are so complicated that make the advanced research centers stray in the ocean of such changes. Dipping deep and wide in brain chemistry aiming to see these changes and why they occur increases the mystery and when we want to manage accordingly, we increase the wet of the clay, by the introduced chemicals as a drugs or medicines that are prescribed as a standard solutions to the conditions we mentioned. Spoiling what is spoiled! This pathologic chemistry will be corrected by stopping the triggering agent by the own body corrective buffering system (the puffer system here is not meant by the base excess, it means the power of the body to heal if we help it to get rid from the offending environment) this is the main line, secondary management lines are not excluded but accordingly considered.

\section{Conclusion}

According to my work the aberration in the school aged mental unwanted outcome in its wide and deep levels are in soul due to low grade cerebritis focal or global and due to mainly to chronic brucellosis in Iraq and as a logic in any area that Brucella is underestimated! This means, whom say we do not have Brucella, let him re-calculate his/her evaluation wherever on the globe. I am actively trying to widen the screen test both to the patients as a horizontal level and increase the number of screened intracellular bacteria by Micro-array technique to stand on a wide platform of such interpretation to the mental problems.

\section{Recommendation}

I welcome cooperation and interpretation sharing.

\begin{tabular}{|l|l|}
\hline SJPBS & $\begin{array}{c}\text { Scholarly Journal of Psychology } \\
\text { and Behavioral Sciences }\end{array}$ \\
Assets of Publishing with us
\end{tabular}

